\title{
BIM Bamboo: a digital design framework for bamboo culms
}

Rodolfo Lorenzo MSc, PhD

Lecturer, Department of Civil, Environmental and Geomatic Engineering, University College London, London, UK (corresponding author: r.lorenzo@ucl.ac.uk)

Chuhee Lee MSc, PhD

Research Associate, Department of Civil, Environmental and Geomatic Engineering, University College London, London, UK
Juan G. Oliva-Salinas MArch, Dr.-Ing.

Professor, Facultad de Arquitectura, Universidad Nacional Autónoma de México, Mexico City, Mexico

Marcos J. Ontiveros-Hernandez MArch

Assistant Professor, Facultad de Arquitectura, Universidad Nacional

Autónoma de México, Mexico City, Mexico

For decades bamboo has been identified as one of the most promising alternatives to help reduce the rising demand for industrialised building materials in the global south but numerous technical, normative and cultural challenges have so far prevented its widespread use in construction. In response, significant resources are currently being invested in the development of standardised, highly processed structural bamboo components following the unsustainable model of mass industrialisation prevalent in the global north. As a counterpoint, this research re-examines the structural use of natural bamboo culms against the backdrop of the digital age and postulates a new design and fabrication framework to support the construction of high-quality, sustainable and resilient bamboo structures suitable for the twenty-first century. This framework is based on the principles of building information modelling and is focused on managing, as opposed to forcibly eliminating, the inherent variability of a natural structural element through modern three-dimensional scanning, digital modelling and robotic fabrication. This paper presents the conceptual details of this framework with a particular focus on Mexico, one of the largest emergent economies in the world, as a potential implementation platform.

\section{Introduction}

Two hundred years of intensive industrialisation in the global north have allowed a mere $15 \%$ of the global population to reach a 'very high' human development index. This $15 \%$ uses four times the amount of energy currently consumed by four billion people living in countries categorised as emerging economies (World Bank, 2016). Surprisingly, these emergent economies, all in the global south and with a very different cultural and socioeconomic background, seem to be blissfully following the same model of mass industrialisation. The construction industry in particular flourished under this model, which provides energy-intensive but standardised structural components, and steel, cement and aluminium production now accounts for almost $20 \%$ of all global industrial carbon dioxide emissions (Allwood and Cullen, 2011).

A questionable solution to this problem is the current development of alternative industrialised materials such as epoxybased composite materials, which, in spite of their high strength-to-weight ratio, are comparatively very expensive, not recyclable and their embodied energy is higher than that of steel and aluminium combined (Allwood and Cullen, 2011). Paradoxically, bamboo culms - which are natural, abundant and sustainable high-strength fibre-reinforced composite tubes endemic to all emergent economies (Kuehl et al., 2011) - have been increasingly marginalised and stigmatised as a temporary, low-quality, non-engineered alternative to steel and concrete.
To some extent these attributes, together with the low-cost, workability and good physical and mechanical properties of bamboo culms, have indirectly encouraged these negative perceptions in many parts of the world as research and development activities have been predominantly focused on social and self-build housing (e.g. INBAR, 2002; Kaminski, 2013; Moran, 2015), temporary structures and scaffolding (e.g. Chung and Chan, 2002) and humanitarian and disaster relief projects (e.g. Hodgkin, 2009; Paudel, 2003). In parallel, but at the other end of the design spectrum, a select group of designers and architects has developed remarkable but very bespoke, high-specification projects and temporary pavilions using bamboo culms; such projects require specialist workmanship, long building programmes and comparatively large budgets (e.g. Detail, 2010; Velez, 2000; VTN, 2016).

In line with the design philosophy for industrialised structural components developed in the last century, recent technological and scientific developments are increasingly focused on energy-intensive processes to transform bamboo culms into standardised beams and panels (Aschheim et al., 2010; Sharma et al., 2014; Xiao et al., 2008) in order to overcome the challenges posed by a natural structural element. Limited lifecycle and carbon dioxide footprint analyses of these products have been carried out (van der Lugt and Vogtlander, 2015) but a wider range of independent research is required to reach a conclusion on the environmental impact of these products. 
As a counterpoint, this paper postulates that the digital age provides the ideal setting to develop an alternative high-tech, low-energy design approach to develop high-quality, affordable, sustainable and resilient bamboo structures suitable for the twenty-first century based on managing, as opposed to forcibly eliminating, the inherent variability of a natural structural element. Undoubtedly, empirical knowledge and artisanal building methods have played a vital role in bamboo construction and will continue to inform modern research and development activities. However, it is also important to critically assess the current validity of the predominant focus on self-build schemes in today's increasingly global, urbanised and interconnected world that provides ever-increasing access to affordable modern technologies. Additionally, designers have now unprecedented access to digital modelling, robotic fabrication and other advanced tools that are revolutionising the built environment (Dezeen, 2016) and thus it seems fitting to challenge the common preconception that bamboo culms and these advanced technologies are part of mutually exclusive realms.

The aim of the research outlined in this paper was to take the first step towards the integration of bamboo culms into a modern design environment and the proposed approach to do so stems from the principles of building information modelling (BIM). BIM is 'the process of designing, constructing or operating a building or infrastructure asset using electronic object orientated information' (BSI, 2013) and its fundamental principle consists of sharing this structured information through a model of the built environment asset (Simpson, 2013). For manufactured components, this electronic object-oriented information is generally readily available and standardised but, in the case of bamboo culms, the corresponding information has to be generated from the accurate acquisition and processing of the relevant data describing their variable properties. Managing such data efficiently through appropriate protocols will support the integration of bamboo culms into modern design methods and fabrication processes such as environmental and structural performance analysis, parametric modelling and robotic fabrication. This integration can ultimately support the development of expressive, high-quality designs based on a rational use of bamboo culms in combination with other materials and components.

This paper outlines the research methodology, equipment and procedures proposed to address some of the challenges of construction with bamboo culms together with possible implementation routes in Mexico, one of the largest emergent economies in the world with a vast potential to exploit this truly sustainable natural resource.

\section{BIM Bamboo research project}

BIM Bamboo is a research project to develop the processes required to bring bamboo culms and cutting-edge technology closer together in order to impulse the use of these natural structural elements in the built environment. This research is mainly based on the principles of BIM, which is being widely adopted for the effective management of information throughout the lifecycle of infrastructure projects (e.g. BIS, 2012). The fundamental premise behind BIM is the availability of accurate digital information describing the properties of all project components. In the case of bamboo culms, it is therefore essential to intensively measure and digitise their physical, geometric and mechanical properties to quantify their inherent variability as the first step towards their integration into modern design, fabrication and management platforms.

The main equipment used for this initial stage of the research consisted of a small, high-speed, six-axis KUKA KR 10 R1100 SIXX (KR Agilus) robotic arm with a total payload of $10 \mathrm{~kg}$ (KUKA Robotics, 2016) and an Artec 3D Space Spider scanner (Artec 3D, 2016) with three-dimensional (3D) resolution and point accuracy of up to $0.1 \mathrm{~mm}$ and $0.05 \mathrm{~mm}$ respectively. It is important to note that, even though this technology is considered to be fully transferable based on the socioeconomic and industrial context of most emergent economies, its relatively high specification was chosen to ensure a reliable research benchmark to explore the use of even simpler and more affordable technologies.

\subsection{Physical and geometric properties}

The proposed methodology to determine the geometric properties of individual bamboo culms is through a non-contact, non-destructive, reverse engineering approach based on the intensive measurement of individual bamboo culms using 3D structured light (blue LED) scanning technology. In order to determine the optimum scanning workflow, the 3D scanner was attached to the robotic arm as an efficient and accurate exploratory research tool (Figure 1). The final scanning workflow is being developed informed by this exploratory work and driven by the requirements of speed and flexibility to accommodate the variable diameter and irregular geometry of the poles.

The fundamental data from which the physical features of the poles are extracted is the raw point cloud captured by the scanner at a maximum frame rate of 7.5 frames $/ \mathrm{s}$ and 1000000 points/s. A section of a $4 \mathrm{~m}$ long $60-70 \mathrm{~mm}$ diameter pole is shown in Figure 2, together with the results of its rendered scan showing the capability of modern scanners to capture colour and texture. Digitising these features for individual poles can support the detection of major defects and also the virtual exploration of the aesthetic and architectural effect created by exposed bamboo poles on a project. The $3 \mathrm{D}$ mesh required for any further manipulation is generated from the raw point cloud using the scanner's proprietary software Artec Studio 10 (Artec 3D, 2016). Apart from the broad range of commercial point-cloud processing software currently available, robust open-source applications are also widely accessible nowadays (e.g. pointclouds.org, meshlab.sourceforge.net). 
Figures 3(a) and 3(b) show the captured point cloud of a portion of a bamboo pole and the corresponding triangulated mesh derived from it. Mesh models provide a very accurate geometric representation of the scanned object and are widely used in museology and similar applications. However, these models are impractical to manage a digital database of bamboo stockpiles due to their large file sizes and they require further processing to extract the relevant information for structural applications. Therefore, a Python script (PSF, 2015) has been developed within the modelling software Rhinoceros (RMNA, 2015) to extract key non-uniform rational B-spline (NURBS) curves (Wikipedia, 2016a) from the mesh model in order to transform it into a more practical boundary representation (BRep) model (Wikipedia, 2016b). The model in Figure 3(c) shows the BRep model obtained from the mesh in

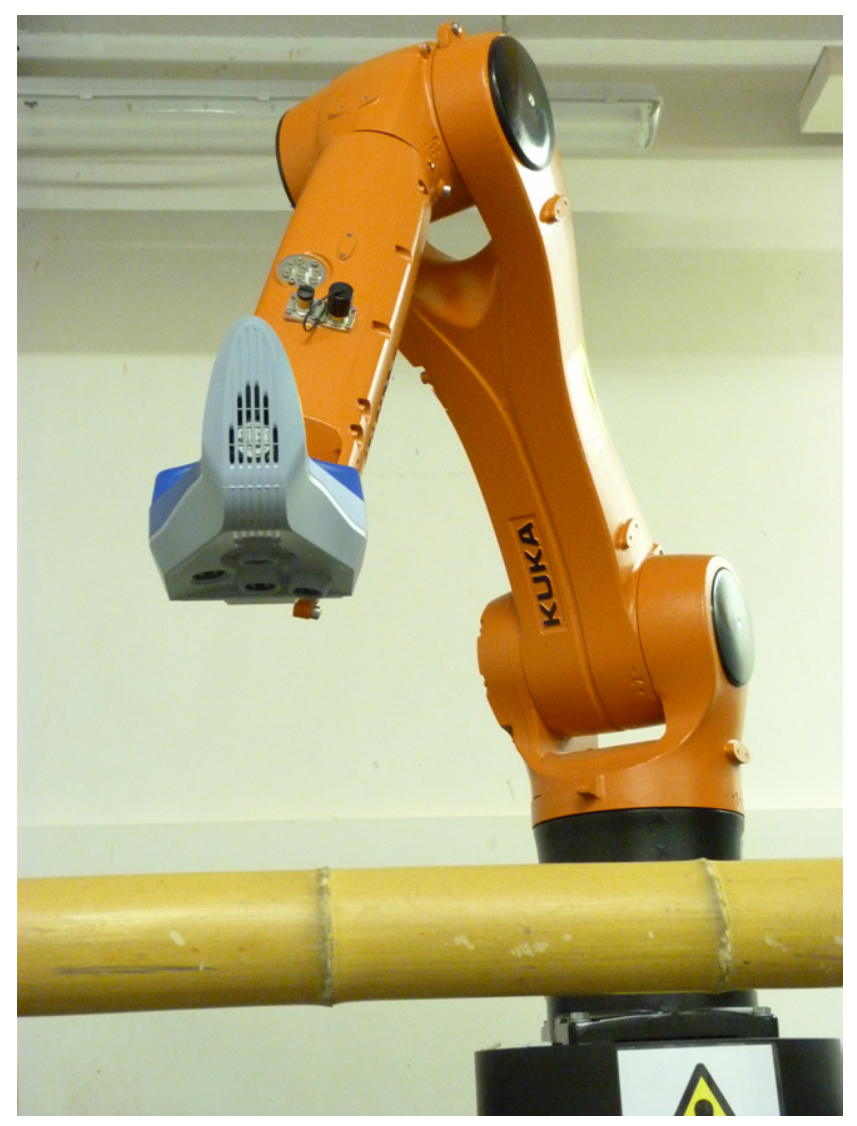

Figure 1.3D scanner attached to robotic arm
Figure 3(b), including the NURBS curves in the nodes and internodes areas from which it was generated. Previous studies (Amada et al., 1997; Chung and Yu, 2002) have indicated that the wall thickness of bamboo poles varies approximately linearly along their length and therefore the wall thickness of the BRep model is based on a linear interpolation of the cross-sections at the exposed ends of the poles. Preliminary fabrication trials based on the bamboo BRep models developed so far support this assumption, which will be continually assessed during the different stages of the research project. The final dataset extracted from the digital scan of the poles is their centroidal axis together with the position of nodes and the mid-point within each internode, as shown in Figure 3(d). These data are intended to form the basis of the finite-element discretisation required to carry out a global structural analysis taking into account the actual geometric imperfections and variation of cross-sectional properties along each bamboo pole. The dashed lines in Figure 3(d) show the hollow cross-sections suggested for the internodal finite elements and the solid cross-sections of the nodal membranes that are incorporated in the BRep model for their design and fabrication significance.

The geometric information encapsulated in the BRep model and the centroidal axis discretisation (Figures 3(c) and 3(d)) is essential for the accurate modelling and fabrication of bamboo structures and thus it constitutes the backbone of the digitalisation of bamboo poles as structural elements.

\subsection{Mechanical properties}

Testing of small clear specimens to evaluate the physical and mechanical properties of timber has always played a very important role in the development of timber construction due to the great variety of species, material variability, changing supply conditions, ease of comparison of variables and so on (ASTM, 2014). In comparison, our understanding of the physical and mechanical properties of bamboo is still in its infancy and much more test data are required to gain additional confidence in the assessment of the structural reliability of bamboo culms while minimising conservativism and maximising structural use of the culm.

Automatic workflows to efficiently and accurately machine small test samples at the free ends of bamboo culms are being developed as part of this research using the robotic arm with appropriate end effectors as a versatile computer numerical 


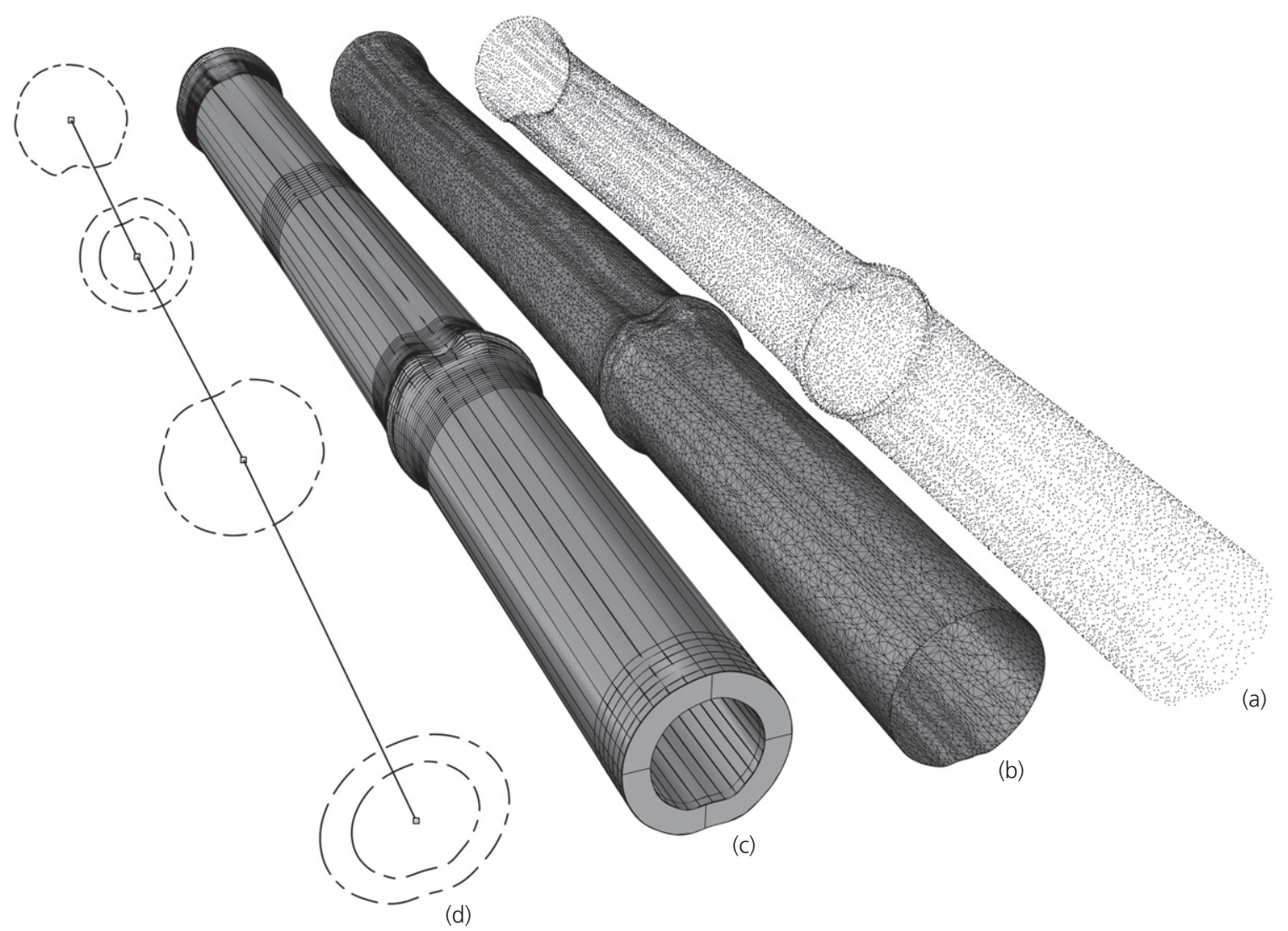

Figure 3. Digital bamboo pole models: (a) point cloud; (b) mesh;

(c) BRep; (d) centroidal axis

control (CNC) router. These workflows will include guidance and recommendations on tooling and toolpath strategies as well as milling feeds and speeds. The machining process will rely on the digital models of the culms and the test results will be an additional element of the digital data associated with the properties of individual poles. The goal of intensive small-sample testing is to increase basic understanding of the material through extensive databases generated in plantations with small-scale equipment, which can then be used as part of plantations' quality assurance procedures and will ultimately inform the ongoing development of international standards for bamboo culms (e.g. ISO, 2004). The proposed tests will follow the Chinese bamboo testing standard (MCBI, 2007), including moisture content, density, compressive strength and elastic modulus (parallel and perpendicular to the fibres) and tensile strength and elastic modulus (parallel to the fibres) among others. The relevant toolpaths and workflows for test specimens to determine the transverse mechanical properties and anisotropic elastic constants of bamboo culms proposed by Sharma et al. (2013) and Garcia et al. (2012) respectively will also be explored.

Small clear specimen testing can provide particularly interesting data for bamboo because, compared with timber, its anatomical structure is rather simple as growth is very fast and originates from a primary shoot without any secondary growth. Density and fibre content have been identified as features that have a significant influence on the mechanical properties of bamboo (Liese, 1998) and an automated image processing procedure is thus being developed to determine the fibre content of test specimens. As shown in Figures 4(a) and 4(b), the structure of the internode consists of vascular bundles with dark sclerenchymatous cells embedded in a clearer parenchymatous ground tissue (Liese, 1998). High-strength fibres occur at or near the vascular bundles, which are smaller and more numerous at the periphery of the culm and larger and fewer towards the inside. Figure 4(c) shows the fibres (or more precisely, the vascular bundles) from which the fibre content of the samples will be estimated. Bamboo culms generally taper from base to tip and the wall of the internodes decreases with height. Even though the total number of vascular bundles also decreases with height, the density of vascular bundles per unit area increases and thus, contrary to current practice, the proposed sampling will cover as much of the culm as practically possible as thinner poles could be appropriate for particular structural applications.

The anatomical structure of bamboo has been previously idealised as a composite material with axially oriented fibres 


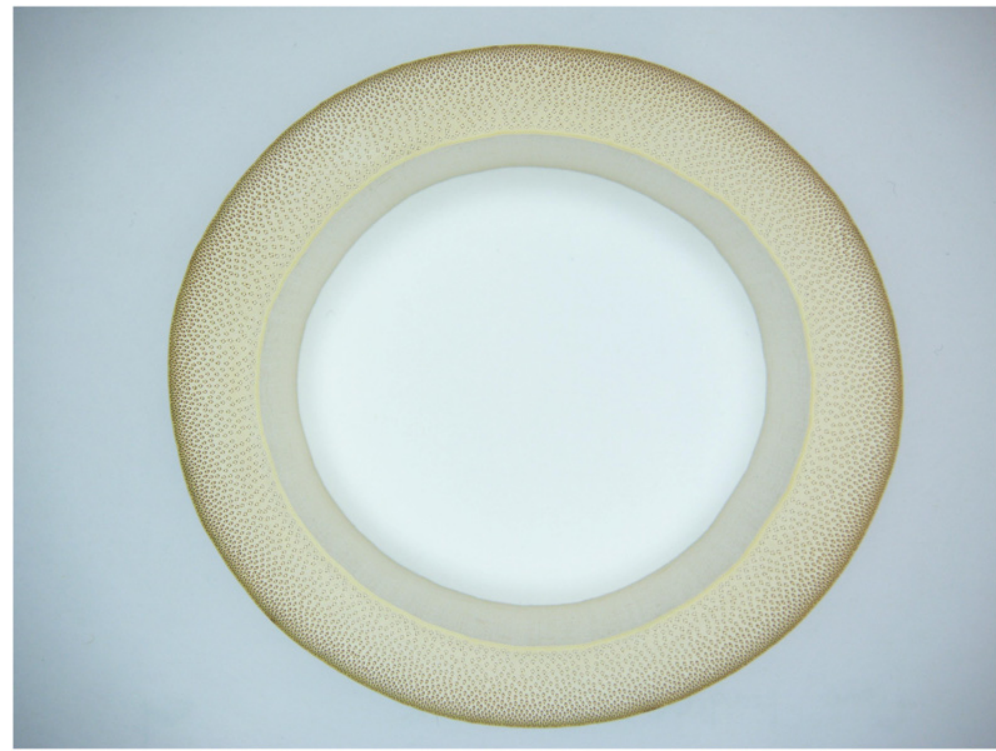

(a)

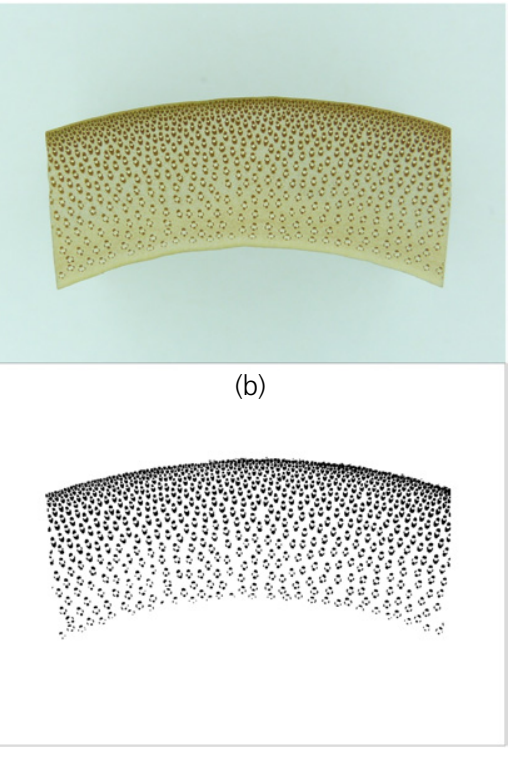

(c)

Figure 4. Bamboo cross-section (a) and small $25 \mathrm{~mm}$ sample (b)

with vascular bundles after image processing (c)

embedded in a parenchymatous matrix and studied based on small-sample testing (e.g. Amada et al., 1997; Dixon and Gibson, 2014). This research will expand this idealisation from the material to the element scale in order to take into account the effect of shape and form on the stiffness of bamboo poles. The proposed model for the poles is that of a composite thin laminate tube consisting of concentric transversely isotropic plies (Kollar and Springer, 2003). The varying elastic constants of each ply will be determined from the small clear specimen tests assuming a variation proportional to the radial fibre content distribution across the wall. This model will be developed and validated during the research as a tool to determine the stiffness matrix of bamboo as an orthotropic composite material for 2D (plates) finite-element models of the poles suitable for structural sub-frame analyses. In addition, this model will also determine the equivalent axial and bending stiffness of 1D finite-element models of the poles (Figure 3(d)) for the more common global structural analyses.

\subsection{BIM integration}

The construction industry is currently generating similar, albeit simpler, digital information for manufactured structural components. Apart from the physical, geometric and mechanical data described so far, this information also incorporates relevant quality control and asset management data. For bamboo poles, these data are expected to describe the species name, plantation location, date of felling and despatch, age, treatment process and so on, and should be an integral part of the bamboo producers' quality assurance system and the stakeholders' maintenance plan for a natural structural element.
One of the main challenges in the construction industry that BIM seeks to address is the interoperability of this digital information across a vast array of software platforms now used by designers. The development of the Industry Foundation Class (IFC) as a standard, non-proprietary method of structuring computable information (buildingSMART, 2013) is expected to solve this challenge. As such, this research will follow the latest IFC specification (IFC4) to generate digital files for bamboo poles to encourage and facilitate the use of bamboo culms in a modern design process. Particularly relevant for bamboo structures is the early incorporation of fabrication requirements into the design process to allow for a more efficient material selection and improve the overall quality and reliability of connections and other components. The results of a preliminary fabrication trial are shown in Figure 5 in which the end detail of a bamboo pole is digitally modelled in the BRep of a bamboo pole (Figure 5(a)), milled using a numerically controlled router (Figure 5(b)) and re-scanned to obtain an as-built record of the piece (Figure 5(c)). This process could become the basis of rapid prototyping to encourage designers to efficiently develop, test and analyse new ideas, especially for culm connections where significant research and development work is still required.

The prescriptive codes and standards that govern structural engineering designs are hindering innovation within the profession and there is therefore a strong need to develop a new design philosophy to reduce unnecessary design constraints. The Structural Engineering Institute (SEI) of the American Society of Civil Engineers (ASCE) advocates a change towards performance-based design codes and standards to 'encourage 


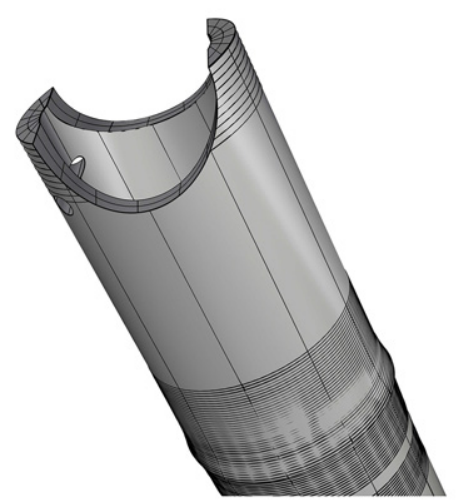

(a)

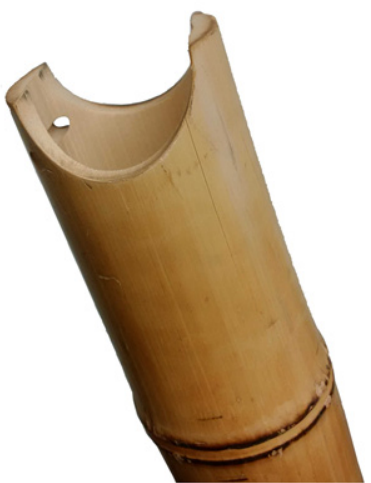

(b)

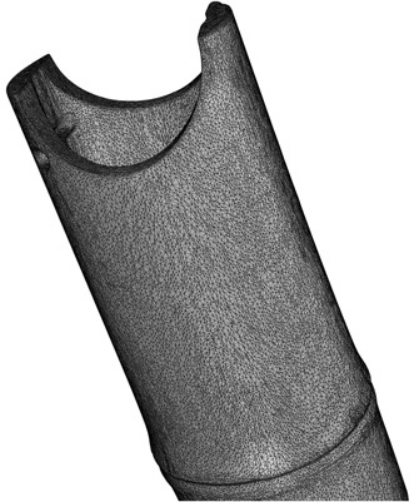

(c)

Figure 5. BRep model of the end detail of a bamboo pole (a), machined sample (b) and corresponding scanned model (c)

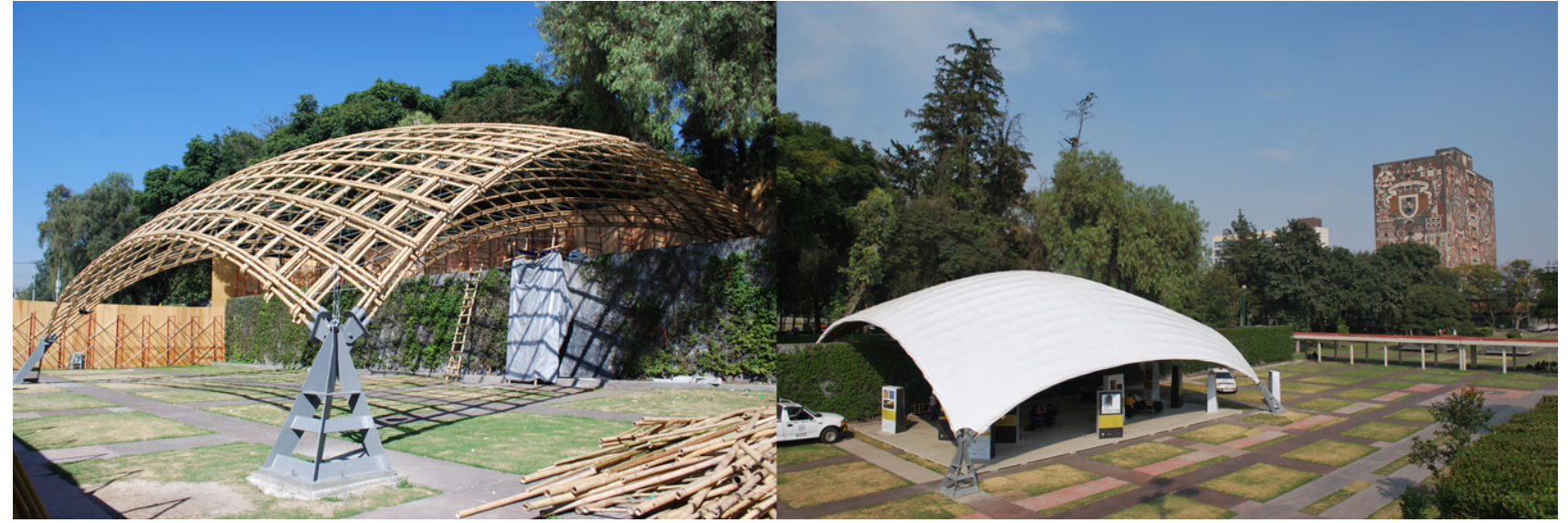

(a)

Figure 6. Bamboo pavilion during construction (a) and in service (b) at the National University of Mexico in 2010

creative thinking to achieve innovative, cost-efficient, environmentally-sensitive, and sustainable designs, while blunting the ongoing trend toward codes that marginalize our profession' (ASCE, 2013). The interoperability of a BIM framework for bamboo culms can support this new design philosophy and push the advancement of this natural material through modern digital modelling, robotic prototyping and testing, numerical simulations and performance monitoring.

\section{Research implementation - Mexico}

The use of bamboo in construction in Mexico, and most Latin-American countries, dates back to pre-Columbian times when bamboo was considered a viable construction material endemic to the region. The Spanish conquest brought masonry and timber construction, and bamboo was stereotyped as a low-quality material and relegated to rural areas. The traditional Colonial style was eventually replaced by modern construction systems mostly based on reinforced concrete and masonry and promoted by governmental low-income housing programmes that disregarded bamboo as a formal construction material. The only significant exception has been self-build constructions in response to natural disasters in which the use of bamboo is accepted for walls and other load-bearing elements and the traditional palms or tiles are generally replaced by corrugated metal roofing.

The first example of a modern, long-span bamboo structure developed in Mexico was a temporary pavilion built in 2010 to commemorate the centenary of the National University of Mexico (UNAM) (Figure 6). The pavilion was designed by 
staff and students of UNAM's faculty of architecture, whose interest in bamboo as a sustainable construction material dates back over two decades. More recently, the faculty of engineering in the same institution has joined these continuing efforts, contributing to the study of the physical and mechanical properties of native Mexican bamboo species (Oliva-Salinas et al., 2015).

Currently, Mexico is an ideal test bed for structural bamboo research not only because of its suitable geographic location and current rate of economic growth but also because it typifies the predicted global trends for developing countries with its $80 \%$ urban population and very unequal society in which $50 \%$ of the population lives under the national poverty line (World Bank, 2016). The prevalence of low living standards is one of the main contributors to overall poverty in developing countries and improving them will demand a vast amount of construction materials over the coming decades. The socioeconomic conditions in Mexico therefore seem suitable to explore new directions in structural bamboo design and to engage with potential stakeholders in order to maximise the potential impact of this research.

\section{Conclusions}

The research project outlined in this paper seeks to introduce a technological framework to support the adoption of whole bamboo culms in high-quality, affordable and sustainable designs in the built environment. This framework relies on the use of cutting-edge but affordable technologies and is intended to support the creativity of designers to fully develop the potential of this natural and renewable resource.

More generally, this research aims to establish a new direction in international research on structural bamboo by steering away from the numerous technocratic and frequently culturally detached solutions developed by foreign research projects trying to solve some of the complex socioeconomic problems prevalent in the global south - housing shortages, urban slums, rural underdevelopment and so on. Instead, the aim of this research is to facilitate dialogue to collaboratively develop a modern mechanism that will enable countries in this region to adopt bamboo culms as a viable structural element to incorporate in their own solutions to these complex problems.

The construction industry currently faces major challenges to reduce its negative impact on the environment and part of the solution lies in promoting a more rational use of our remarkable industrialised materials and components in combination with more sustainable resources. This seems to be an appropriate moment in time to harness the potential of affordable modern technologies and to capitalise on, but also question, our industrial heritage to ensure the effective future development of these resources.

\section{Acknowledgement}

The work presented in this paper is supported by the UK Engineering and Physical Sciences Research Council (EPSRC) (grant EP/M017702/1).

\section{REFERENCES}

Allwood J and Cullen J (2011) Sustainable Materials - with Both Eyes Open: Future Buildings, Vehicles, Products and Equipment - Made Efficiently and Made with Less New Material. UIT Cambridge Ltd, Cambridge, UK.

Amada S, Ichikawa Y, Munekata T, Nagase $Y$ and Shimizu H (1997) Fibre texture and mechanical graded structure of bamboo. Composites Part B: Engineering 28B(1-2): 13-20.

Artec 3D (2016) https://www.artec3d.com/ (accessed 22/09/2016).

ASCE (American Society of Civil Engineers) (2013) A Vision for the Future of Structural Engineering and Structural Engineers: A Case for Change. Structural Engineering Institute, American Society of Civil Engineers, Reston, VA, USA. See http://www.asce.org/uploadedFiles/ visionforthefuture.pdf (accessed 10/03/2016).

Aschheim M, Gil-Martin LM and Hernandez-Montes E (2010) Engineered bamboo I-joists. Journal of Structural Engineering 136(12): 1619-1624.

ASTM (2014) D143: Standard test methods for small clear specimens of timber. ASTM International, West Conshohocken, PA, USA.

BIS (Department for Business, Innovation and Skills) (2012) Industrial Strategy: Government and Industry in Partnership: Building Information Modelling. BIS, London, UK. See http://www.gov.uk/government/publications/ building-information-modelling (accessed 08/03/2016).

BSI (2013) PAS 1192-2:2013: Specification for information management for the capital delivery phase of construction projects using building information modelling. BSI, London, UK. See http://shop.bsigroup. com/forms/PASs/PAS-1192-2 (accessed 01/03/2016).

buildingSMART (2013) IFC Implementation. See http://www. buildingsmart-tech.org/implementation/implementations (accessed 10/03/16).

Chung KF and Chan SL (2002) Design of Bamboo Scaffolds. International Network for Bamboo and Rattan, Beijing, China.

Chung KF and Yu WK (2002) Mechanical properties of structural bamboo for bamboo scaffoldings. Engineering Structures 24(4): 429-442.

Detail (2010) Bamboo pavilion for the Expo Shanghai. Detail Magazine 10(6): 1046-1052.

Dezeen (2016) http://www.dezeen.com/future-makers (accessed 22/09/2016).

Dixon PG and Gibson LJ (2014) The structure and mechanics of Moso bamboo material. Journal of the Royal Society, Interface 11: 20140321. 
Garcia JJ, Rangel C and Ghavami K (2012) Experiments with rings to determine the anisotropic elastic constants of bamboo. Construction and Building Materials 31: 52-57. Hodgkin D (2009) A Manual on the Humanitarian Use of Bamboo in Indonesia. Humanitarian Bamboo, Sewon, Indonesia.

INBAR (International Network for Bamboo and Rattan) (2002) Low-Cost Bamboo-Based Houses. INBAR, Beijing, China. ISO (International Organization for Standardization) (2004) ISO 22157-1:2004: Bamboo - Determination of physical and mechanical properties - part 1: requirements. ISO, Geneva, Switzerland.

Kaminski S (2013) Engineered bamboo houses for low-income communities in Latin America. The Structural Engineer 91(10): 14-23.

Kollar LP and Springer GS (2003) Mechanics of Composite Materials. Cambridge University Press, Cambridge, UK.

Kuehl Y, Henley G and Yiping L (2011) The Climate Change Challenge and Bamboo: Mitigation and Adaptation. International Network for Bamboo and Rattan, Beijing, China.

KUKA Robotics (2016) http://www.kuka-robotics.com (accessed 22/09/2016).

Liese W (1998) The Anatomy of Bamboo Culms. International Network for Bamboo and Rattan, Beijing, China.

MCBI (Ministry of Construction and Building Industry) (2007) JG/T 199: Testing Methods for Physical and Mechanical Properties of Bamboo Used in Building MCBI, Beijing, China (in Chinese).

Moran J (2015) The Anatomy of Bamboo Culms. International Network for Bamboo and Rattan, Beijing, China.

Oliva-Salinas JG, Hernandez-Hernandez A, Ontiveros-Hernandez MJ and Trujillo-Barragan M (2015) Sustainable construction materials and their application to architectural and structural design. In Proceedings of the IASS Annual International Symposium: Future Visions. Koninklijk Instituut van Ingenieurs, Amsterdam, the Netherlands.
Paudel SK (2003) Bamboo Emergency Shelter - Construction Manual. International Network for Bamboo and Rattan, Beijing, China.

PSF (Python Software Foundation) (2015) Python. Software Version 3.5.1. Python Software Foundation, Beaverton, OR, USA.

RMNA (Robert McNeel and Associates) (2015) Rhinoceros. Software Version 5.0. Robert McNeel \& Associates, Seattle, WA, USA.

Sharma B, Harries KA and Ghavami K (2013) Methods of determining transverse mechanical properties of full-culm bamboo. Construction and Building Materials 38: $627-637$.

Sharma B, Gatóo A, Bock M, Mulligan H and Ramage MH (2014) Engineered bamboo: state of the art. Proceedings of the Institution of Civil Engineers - Construction Materials 168(2): 57-67.

Simpson M (2013) A definition of BIM. The Structural Engineer 91(11): 6-9.

van der Lugt P and Vogtlander JG (2015) The Environmental Impact of Industrial Bamboo Products. Life-Cycle Assessment and Carbon Sequestration. International Network for Bamboo and Rattan, Beijing, China.

Velez S (2000) Grow Your Own House. Vitra Design Museum, Weil am Rhein, Germany.

VTN (Vo Trong Nghia Architects) (2016) votrongnghia.com (accessed 22/09/16)

Wikipedia (2016a) Non-Uniform Rational B-Spline. See http://en.m.wikipedia.org/wiki/Non-uniform_rational_ B-spline (accessed 10/03/16).

Wikipedia (2016b) Boundary Representation. See http:// en.m.wikipedia.org/wiki/Boundary_representation (accessed 10/03/16).

World Bank (2016) Data. The World Bank, Washington, DC, USA. See http://data.worldbank.org/ (accessed 01/03/2016).

Xiao Y, Inoue M and Paudel SK (eds) (2008) Modern Bamboo Structures. CRC Press, London, UK.

\section{HOW CAN YOU CONTRIBUTE?}

To discuss this paper, please email up to 500 words to the editor at journals@ice.org.uk. Your contribution will be forwarded to the author(s) for a reply and, if considered appropriate by the editorial board, it will be published as discussion in a future issue of the journal.

Proceedings journals rely entirely on contributions from the civil engineering profession (and allied disciplines). Information about how to submit your paper online is available at www.icevirtuallibrary.com/page/authors, where you will also find detailed author guidelines. 